Clinical Vistas

\section{Tache noire}

A 47-year-old man presented to the emergency department with fever, chills, drenching sweats and erythema over his left buttock and groin. He was taking cephalexin, which had been prescribed 3 days earlier for presumed cellulitis, with no clinical response. The patient informed us that he had been on a bush safari in South Africa io days earlier. Careful physical examination revealed a black crusted lesion Io $\mathrm{mm}$ in diameter with a surrounding red halo on his left buttock (Figure I). Initial bloodwork indicated mild leukopenia (leukocyte count I. $7 \times \mathrm{IO}^{9} / \mathrm{L}$ ) and transaminitis (aspartate aminotransferase level $67 \mathrm{U} / \mathrm{L}$, alanine aminotransferase level $97 \mathrm{U} / \mathrm{L}$ ). Malaria films were negative. We made a clinical diagnosis of African tick-bite fever and prescribed a I-week course of doxycycline. The patient's symptoms resolved within 48 hours. Serologic testing of samples taken in the acute phase were negative for rickettsial antibodies, but we detected Rocky Mountain spotted fever antibody titres ( $\operatorname{lgM} \geq 1 / 64, \operatorname{IgG} \geq 1 / 256)$ in convalescent serum samples.

African tick-bite fever is caused by Rickettsia africae, one of the spotted fever group of the Rickettsia species, and is transmitted in sub-Saharan Africa by Amblyomma ticks. ${ }^{1}$ About I week after a tick bite, an influenza-like syndrome with fever, fatigue, headache and myalgia develops. A black eschar, or tache noire, occurs at the site of the tick bite. Multiple bites may result in several eschars. Lymphadenitis in the nodes draining the eschar site can occur, and rashes, both adjacent to the eschar and generalized, are relatively common.

Diagnosis of African tick-bite fever is usually established on clinical grounds. Nonspecific laboratory abnormalities include lymphopenia and, less commonly, transaminitis ( $40 \%$ of cases)

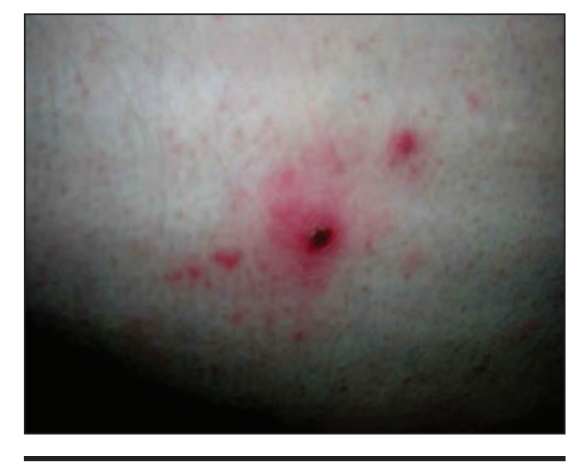

Figure 1: Black crusted lesion, or tache noire, $10 \mathrm{~mm}$ in diameter, on the left buttock of a 47-year-old man.

and thrombocytopenia (20\% of cases). Serologic tests for $R$. africae are not commercially available; however, since there is cross-reactivity between $R$. africae and Rocky Mountain spotted fever antibodies, positive results for those antibodies can support the clinical diagnosis. The clinical presentation of African tick-bite fever may be distinguished from Rocky Mountain spotted fever (caused by Rickettsia rickettsii) by the presence of an eschar, and from Mediterranean spotted fever (caused by Rickettsia conorrii) if multiple eschars are present. Although performing a biopsy of the eschar is not common, biopsy results can also distinguish African tick-bite fever from Mediterranean spotted fever. ${ }^{2}$ In addition, thick and thin films and blood cultures are required to rule out competing diagnoses, including malaria and typhoid fever.

Tourism in South Africa, the most common source of African tick-bite fever cases, has increased dramatically since the end of apartheid; in 2005 , 67400 Canadians travelled to that country. ${ }^{3}$ The only prospective study to date found that African tick-bite fever occurred in $4 \%$ of travellers to subSaharan Africa. Of note, the classic eschar seen in the case of our patient was found in the cases of only half of those infected. ${ }^{4}$ Risk factors for infection include game hunting and travel to southern Africa from November to April.

Travellers can protect themselves from African tick-bite fever by wearing long-sleeved clothing; however, in hot climates adherence may be difficult. The role of topical insect repellents in preventing tick bites is unclear. A recent study found that products containing more than $20 \%$ diethyltoluamide (DEET) provided substantial but shortterm protection. ${ }^{5}$

This case emphasizes the need to obtain a travel history for all febrile patients, including a detailed timeline and exposure profile. African tick-bite fever should be considered in patients with fever, headache and myalgia who have travelled to disease-endemic countries. When present, an eschar is a helpful clue and so should be sought carefully. Therapy with doxycycline (Ioo $\mathrm{mg}$ twice a day for 7 days) typically leads to rapid improvement; however, a subset of patients may experience a prolonged convalescence characterized by arthralgia and malaise.

\section{Nick Daneman MD}

Department of Medicine, Infectious Diseases

Sunnybrook Health Sciences Centre

Toronto, Ont.

\section{Robert Slinger MD}

Department of Microbiology,

Infectious Diseases

Children's Hospital of Eastern Ontario Ottawa, Ont.

This article has been peer reviewed.

Competing interests: None declared.

Acknowledgements: We thank Jennifer Morson for the photograph of the tache noire.

\section{REFERENCES}

I. Raoult D, Fournier PE, Fenollar F, et al. Rickettsia africae, a tick-borne pathogen in travelers to subSaharan Africa. N Engl J Med 200I;344:I504-10.

2. Lepidi H, Fournier PE, Raoult D. Histologic features and immunodetection of African Tick-bite fever eschar. Emerg Infect Dis 2006; I2:1332-7.

3. International travel survey. Ottawa: Statistics Canada; 2006. Cat no 66Cooor.

4. Jensenius M, Fournier PE, Vene S, et al. Norwegian African Tick Bite Fever Study Group. African tick bite fever in travelers to rural sub-Equatorial Africa. Clin Infect Dis 2003;36:I4II-7.

5. Jensenius M, Pretorius AM, Clarke F, et al. Repellent efficacy of four commercial DEET lotions against Amblyomma hebraeum (Acari: Ixodidae), the principal vector of Rickettsia africae in southern Africa. Trans R Soc Trop Med Hyg 2005;99:708-II. 